\title{
An interdisciplinary approach to
} improving the quality of life in Postural Orthostatic Tachycardia Syndrome: A

\section{case study}

\section{Turner, C}

http://hdl.handle.net/10026.1/16455

\subsection{3/cssep.2020-0010}

Case Studies in Sport and Exercise Psychology

Human Kinetics

All content in PEARL is protected by copyright law. Author manuscripts are made available in accordance with publisher policies. Please cite only the published version using the details provided on the item record or document. In the absence of an open licence (e.g. Creative Commons), permissions for further reuse of content should be sought from the publisher or author. 
IMPROVING QOL IN POTS

4 An interdisciplinary approach to improving the quality of life in 5 Postural Orthostatic Tachycardia Syndrome: A case study 6 7

8 
An interdisciplinary approach to improving the quality of life in Postural Orthostatic Tachycardia Syndrome: A case study

\begin{abstract}
Postural Orthostatic Tachycardia Syndrome (POTS) is a debilitating condition affecting the autonomic nervous system that causes a series of symptoms such as blurred vision, brain fog, chest pain, headaches, shortness of breath, fatigue, syncope and rapid heart rate. These symptoms can lead to diminished daily activity, daytime fatigue, poor sleep quality, and increased suicidal tendencies. Among the physical symptoms, POTS patients present decreased quality of life (QOL), increased prevalence of depression and elevated anxiety (Anderson, et al, 2014). This case study documents an interdisciplinary approach to treating a 39-year-old female POTS patient with an eight-week intervention program and a further four-week follow-up. The intervention investigated the combined effects of Functional Imagery Training (FIT) and physical exercise on the patient's QOL. Following completion of the program, the subject improved in all four QOL components and this change was maintained over time when compared to baseline measures. The program demonstrated that high levels of exercise adherence beyond the intervention can be achieved when combining FIT and exercise, regardless of the exercise intolerant characteristics presented by a POTS patient.
\end{abstract}

Keywords: postural orthostatic tachycardia syndrome, quality of life, exercise, functional imagery training 
IMPROVING QOL IN POTS

\section{Overview of POTS}

Postural Orthostatic Tachycardia Syndrome (POTS) is a condition that affects $0.2 \%$ of the population, resulting from disturbances in the autonomic nervous system, presenting as a heterogeneous group of disorders with similar characteristics. The constellation of symptoms that arise as a result of this condition include blurred vision, brain fog, chest pain, headaches, severe fatigue and a rapid heart rate (HR) (Anderson, Lambert, Sari, Dawood, Esler et al., 2014; Raj, 2013). These symptoms make everyday living extremely challenging for POTS patients, with quality of life (QOL) severely impacted (Flack \& Fulton, 2018; Moon, Kim, Byun, Sunwoo, Lim et al., 2016). Symptoms often occur when patients stand upright, resulting in inadequate vasoconstriction of blood vessels (particularly in the legs and core), due to muscle deconditioning and/or peripheral denervation. At present all medicines used to treat POTS have concerning side effects, some of which may exacerbate symptoms (Raj, 2013). Research indicates that short-term exercise (Galbreath, Shibata, VanGundy, Okazaki, Fu et al., 2011) could alleviate symptoms, and cognitive behavioural therapies including goal setting (Kizilbash, Ahrens, Bruce, Chelimsky, Driscoll et al., 2014) would be specifically beneficial for managing POTS and improving QOL.

\section{Context and Research Team}

As part of a larger scale trial examining the benefits of exercise and Functional Imagery Training (FIT); an approach that aims to enhance self-efficacy and intrinsic motivation by exploring tangible goals, a potential participant was identified as having POTS. Due to the multitude of health-related complications including cardiac disorders and the research teams' prior lack of POTS knowledge, this participant (R.L.) did not meet the entry criteria because of her current health condition. The second author suggested the possibility of an adapted study, specific to R.L.'s needs if 


\section{IMPROVING QOL IN POTS}

an interdisciplinary team could be formed and ethical clearance granted. The study aimed to investigate if FIT plus exercise improves the QOL in a patient diagnosed with POTS.

The project was promptly approved by the institutional ethics committee on the proviso that a first-aider be present during each exercise session. A case study project was then offered as an alternative to provide individual support necessary for POTS. Prior to the initial meeting a detailed information sheet and consent form explaining the protocols of the study was emailed to the subject. This also included a clear statement explaining FIT sessions would be audio recorded.

In the weeks pending ethical clearance, an interdisciplinary team of nine formed to devise and execute the treatment intervention. The team was brought together and managed by the second author, a chartered psychologist (British Psychological Society; Division of Academics, Teachers and Researchers) who directs a degree in sports rehabilitation and supervises final year projects. The second author will be referred to as 'the psychologist'. The psychologist has completed $>500$ clinical hours of Motivational Interviewing (MI) training including fidelity checks and is a FIT practitioner. A trainee psychologist studying for a Ph.D in psychology and FIT practitioner was responsible for data collection and fidelity checks to add objectivity to the approach.

Two certified sports therapists (Sports Therapy Organisation) with a combined experience of 32 years, who own private practices, and are trained in special populations (e.g., cardiovascular disease) agreed to assist. The first author, one of the sports therapists, took responsibility for project logistics, such as timetables and general communication between all parties. Three conditioning coaches were undergraduate students supervised by a National Strength and Conditioning 


\section{IMPROVING QOL IN POTS}

83 Association (NSCA) Coach, who is also lecturer in the subject. The medical doctor

84 (National Health Service), a Consultant in Acute and General Medicine, acted as a

85 sounding board and is a leading specialist in POTS.

The collaborative team realised the potential for adopting an interdisciplinary approach and weekly meetings evolved to share information and practice, although not all members could always attend. Collectively, the team developed an evidencedbased intervention to improve health and psychological factors. General exercise has shown to benefit numerous health conditions such as: type 2 diabetes, depression, some cancers and heart disease (Agarwal, 2012; Pal, Radavelli-Bagatini, \& Ho, 2013), and specific studies (Fu, VanGundy, Shibata, Auchus, Williams et al., 2011; Shibata, Fu, Bivens, Hastings, Wang et al., 2012) provide guidance for working with POTS patients. For psychological support, goal-centred motivational imagery is beneficial for behavioural change and motivation to goal adherence (Andrade, Khalil, Dickson, May, \& Kavanagh, 2016). As the psychology practitioners were trained in FIT, it was a natural starting point to explore motivation before focusing on tangible goals. It was therefore the aim to merge physiological and psychological interventions to create an interdisciplinary approach.

\section{Philosophical Application}

The interdisciplinary nature of this study involving an amalgamation of both psychological and physiological practices meant that we required a joint philosophical approach. Therefore, recognising there could be conflicting approaches, during the first team meeting the psychologist outlined the holistic stance; to assess the individual not the POTS diagnosis, which was accepted by all practitioners. Collectively, we accepted that there may be similarities between all POTS patients, however, we attempted to treat R.L. as a unique individual by assessing and treating 


\section{IMPROVING QOL IN POTS}

108

131 had previously led a very active lifestyle, attending exercise sessions four to five

132 times per week, including high intensity group exercise and personal training 


\section{IMPROVING QOL IN POTS}

133 sessions. There were even plans put in place to undergo training to become a studio

134 instructor and teach aerobic exercise classes. After collapsing her life quality

135 deteriorated substantially. She continued to feel unwell for prolonged periods of time,

136 stating that her ability to lead a "normal life is unattainable".

137 Receiving the correct diagnosis took many "frustrating months" due to

138 ongoing misdiagnosis from her general practitioner (GP). Her initial GP

139 underestimated the severity of her symptoms, firstly diagnosing fainting with low

140 blood sugar levels suggesting she should "eat some cake" to improve symptoms. Lack

141 of POTS specific understanding is common amongst medical professionals (Kavi,

142 Gammage, Grubb, \& Karabin, 2012). Eventually, at her own financial expense and 13

143 months of "uncertainty" a diagnosis of POTS was confirmed by a specialist

144 consultant. The consultant proposed the condition had manifested due to recent

145 surgery, leaving her vulnerable to autonomic dysfunction. Medications (Midodrine

146 and Fluoxetine), salt, B2, B12 and probiotics were prescribed leading to slight

147 improvements of her condition, albeit with her still feeling fatigued and lacking

148 motivation towards performing physical activity. She demonstrated an understanding

149 that exercise is beneficial for POTS, however conceding "whilst working full-time,

150 work is all I can manage". She expressed fears about losing her job due to long-term

151 absence, losing consciousness, and an inability to perform routine tasks as a

152 consequence of suffering from extreme fatigue.

\section{Case Formation}

154 To treat the person not the condition, R.L. was assessed at week 0, now

155 referred to as baseline, before a treatment plan was collectively put into action. The

156 assessments are reported in order of occurrence, summating in overall case formation

157 which was then developed into a personalised intervention. 


\section{IMPROVING QOL IN POTS}

158

159

160

161

162

163

164

165

166

167

168

169

170

171

172

173

174

175

176

177

178

179

180

181

\section{Measure}

Upon meeting R.L. the study design was recapped, and any questions answered. The WHOQOL-BREF (see Gholami, Jahromi, Zarei, \& Dehghan, 2013) was then administered at baseline with score available in Table 2. The World Health Organisation (Whoqol Group, 1995, p. 1403), defines QOL as:

An individual's perception of their position in life in the context of the culture and value systems in which they live and in relation to their goals, expectations, standards and concerns.

The WHOQOL-BREF questionnaire consisting of 26 self-report items was used to assess domain specific and two overall QOL items. Individual items are scored 1-5 and each domain presents a range of 0-100; the raw scores have been transformed according to manual guidelines (World Health Organisation, 1997). The four domains: physical health, psychological health, social relationships and environment (World Health Organisation, 1997) factorially vary. Physical health questions seek to evaluate an individual's ability to perform daily tasks, energy levels and fatigue, mobility, pain and discomfort, sleep and rest, dependence on medicine and work capacity. Psychological health questions assess the level of positive feelings, negative feelings, self-esteem, ability to think and concentrate, personal beliefs, body image and appearance. Social relationship questions are in relation to personal relationships, social support and sexual activity. Finally, environment questions consider aspects such as: home environment, financial resources, access to health and social care and opportunities for recreation.

\section{FIT}

FIT is a person-centred methodology that utilises the skills from MI,

182 integrating imagery to enhance self-efficacy and foster intrinsic motivation. MI is a 


\section{IMPROVING QOL IN POTS}

183 client-centred counselling technique that aims to reduce resistance and resolve

184 ambivalence towards change using specific systematic processes (cf. Miller \&

185 Rollnick, 2012). When compared to a control group, MI has been found to be

186 significantly better for weight loss (Smith, Heckemeyer, Kratt, \& Mason, 1997), but

187 not as effective when compared to an imagery (FIT) group (Solbrig et al., 2019). Due

188 to the complex motivational needs of POTS patients, FIT can be adapted to support

189 change based on individual cases.

190 The fundamentals of FIT operate within the spirit of MI and the four processes

191 of the interview must be adhered to; engage in conversation, focus on goals, evoke

192 change, and plan for progress. Individuals are supported using skills such as

193 affirmations when they discuss possible solutions to obstacles, further developing

194 self-efficacy. Using Paivio's (1985) motivational and cognitive imagery approach,

195 FIT explores goals by discussing intrinsic values and goals, potential obstacles,

196 personal strengths and overcoming struggles, and future success. At each stage of

197 discussion, the individual is taught how to use multisensory imagery by periodically

198 layering each sense (see Williams, Cooley, \& Cumming, 2013) to enhance the

199 experiences and create feedback from discussion (Lang, 1979). Specifically, imagery

200 focuses on the multisensory experience of goal achievement to foster self-efficacy,

201 and immediate action-based implementations (Duckworth, Kirby, Gollwitzer, \&

202 Oettingen, 2013) which could be beneficial for managing POTS and adhering to

203 exercise. Progressive interview questions like; "what would it be like in six months if

204 you did not change your exercise routine", are later compared to; "imagine a future

205 version of you in six months who did stick to the exercise program. What does that

206 look like? How does it feel? What can you do right now to support a future you?". 


\section{IMPROVING QOL IN POTS}

\section{FIT Interview}

The initial FIT interview is both an assessment and intervention as it involves motivational imagery training. The meeting was audio recorded (and later fully transcribed) for potential client quotes. The audio was shown to other FIT practitioners for training purposes and to check fidelity, which was later reported as 'high'. The transcription was highlighted to show the best fit from the answers given. All quotes were checked with R.L. to ensure meaning was accurate during later interpretation and brief quotes approved by R.L. for publication.

The psychologist began by asking open-ended questions about lifestyle to engage in conversation, progressing to focusing on goals, and then the difference between R.L.'s life now and what she expected it would be like at this point. As the interview continued, imagery was used to contrast between current self and future achievements. To train multisensory imagery, especially motivation specific achievement goals (Paivio, 1985), layered stimulus response training (LSRT;

Williams, Cooley, \& Cumming, 2013) was used to enhance vividness and controllability. Through the FIT process R.L. revealed how the opportunity to enrol on to a study which included exercise, physical therapy and psychological support was the "final roll of the dice", and this was the "most important step in regaining her identity".

R.L. described a desire and need to change, giving reasons such as: "I have to try. I feel guilty of not being able to go out with my children", and a need to be fit and healthy to keep her job and provide for her family. The interview also revealed a loss of confidence in her physical appearance, lack of self-esteem, and an admission that "with POTS life would never be the same again" and was "pretty crap at present". In spite of this, there was an underlying tone of defiance towards her condition, wanting 


\section{IMPROVING QOL IN POTS}

232 to gain "some form of control" to improve her QOL. Towards the end of the session,

233 R.L. set a goal: "I would like to jog continually for five minutes and maybe a long-

234 term goal is to run for $5 \mathrm{~K}$ " and suggested some lifestyle modifications such as

235 "walking 10,000 steps" daily. Jogging was the primary goal, which was imagined

236 through a set of controllable scenarios, and multisensory LSRT delivered to again

237 enhance vividness and controllability. Using a scale from 0 (no image) to 5 (as vivid

238 as having achieved the goal), R.L. was asked to rate her imagery at strategic points,

239 scoring $>3$ at each. A cue was linked to a daily activity, in this case before taking the

240 first sip of coffee, whereby imagery is activated throughout the day to imagine the

241 feeling of success from jogging for five minutes followed by a small implementation

242 strategy. Immediately after this session the physical assessment occurred.

\section{Physical Assessment}

244 The physical assessment determined areas which required improvement

245 through corrective exercise and physical therapy. Assessments included: range of

246 motion (RoM), flexibility, functional movement, muscle activation and special tests.

247 The findings of the physical tests revealed: posterior pelvic tilt, weak: gastrocnemius,

248 gluteus maximus, hamstrings, quadriceps and lower back, limited external rotation at

249 the acetabular femoral joint, painful/stiff lumbar region and sacroiliac joint with

250 hypermobility in the glenohumeral joint. The assessment lasted for 33 minutes, with

251 no exercise occurring at baseline. The results from the assessment went on to develop

252 the physiological intervention delivery. A retest of these assessments did not formally

253 occur, but observations were made based on posture, balance and movement quality

254 which then informed the exercise program. 


\section{IMPROVING QOL IN POTS}

\section{Developing and Delivering the Interventions}

It was not until after completion of the WHOQOL-BREF, FIT interview, and physical assessments at baseline that the interdisciplinary team had enough information to develop a plan for R.L.'s needs. We decided to run combined conditioning and physical therapy, and supportive imagery sessions for eight-weeks following similar exercise protocols (Richardson, Nordon-Craft, \& Carrothers, 2017) and FIT delivery (Rhodes et al., 2018) timelines. At week eight the WHOQOL-BREF would be conducted a second time. At that point, the intervention stopped, and no support provided. Four-weeks later (12-weeks from the first exercise session) we asked the participant to complete the WHOQOL-BREF a final time.

The general plan was to deliver FIT booster sessions for the first 15-minutes,

followed by aerobic conditioning for up to 30-minutes and corrective exercises lasting approximately 15-20 minutes. Although this time was set aside for delivery, we were pragmatic in our approach as there are many obstacles at play.

\section{Psychological Intervention}

From a psychological perspective exercise alone has been shown to decrease depression and anxiety, while enhancing body image and confidence (De Moor, Beem, Stubbe, Boomsma, \& De Geus, 2006; Campbell \& Hausenblas, 2009). Furthermore, exercise is beneficial in negating social withdrawal and low self-esteem whilst presenting opportunities for enhanced self-efficacy and social interactions (Sharma, Madaan, \& Petty, 2006). Although there are many benefits associated with general exercise, individuals with POTS often lack motivation to start, with the primary concern of becoming unconscious during training (Kizilbash et al., 2014). Research (Tito \& Hess, 2017) delivering exercise and assessing QOL has reported a decrease in both physical and psychological domains, but an increase in overall QOL. 


\section{IMPROVING QOL IN POTS}

280 To complement the physical exercise and mobility support intervention, a FIT booster

281 session was delivered weekly which aimed to support motivation to exercise

282 throughout the 8-weeks.

FIT Booster. The FIT booster sessions were conversational, focusing on

284 vividness and controllability of images and were used to monitor goals, reporting

285 findings back to the research group. In weeks 1 and 2, R.L. reported using imagery

286 infrequently as her thoughts were on occasion negative, such as fainting during

287 exercise. A thought parking strategy was implemented whereby R.L. recognises a

288 negative thought and then changes the focus to feelings of accomplishment when she

289 achieves her initial running goal. All imagery regardless of positive or negative

290 outcomes were praised for use, supporting self-efficacy by following the imagery

291 process. During week 3 imagery use was reported as more frequent and controllable,

292 aligned with cue use, and the goal changed to a 10-minute run. By week 4 R.L. was

293 using imagery multiple times daily with the original cue and adaptions such as "when

294 walking the dog, I image running $5 \mathrm{~K}$ with my son, and how that accomplishment

295 would feel, and what he would say”. This goal and cue adaptation occurred for the

296 remainder of the intervention, with the psychologist inputting very little towards the

297 end, merely adding prompts to add a sensory layer where necessary.

\section{Physiological Intervention}

299 Exercise can be particularly beneficial as it has been shown to address many

300 of the common issues that make POTS so debilitating. It is cost effective, simple to

301 implement and has minimal side-effects (Fu \& Levine, 2018). Exercise improves the

302 body's skeletal pump through strengthening the extremities and core, thus improving

303 venous return. It has been found effective in increasing blood volume, ventricle size

304 and baroreflex sensitivity. This can improve stroke volume, vasoconstriction and 


\section{IMPROVING QOL IN POTS}

305 pulmonary circulation which are all critical to negating the symptoms of POTS

306 (Conner, Sheikh, \& Grubb, 2012; Galbreath et al., 2011; Fu \& Levine, 2018). Winker,

307 Barth, Bidmon, Ponocny, Weber et al. (2005) found that following a three-month

308 running program involving Austrian soldiers, 10 out of 16 who had previously

309 experienced dizziness with tachycardia upon standing had a complete recovery from

310 orthostatic intolerance. The control group, who did not jog, reported a resolution of

311 symptoms in just 1 out of 11 soldiers. Considering case studies, there have been

312 projects (e.g., Richardson et al., 2017) which implement specific exercise protocols to

313 treat POTS by monitoring HR and setting tangible targets that motivate exercise

314 adherence, enabling participants to return to full work duties.

315 For replication purposes exercises were selected by R.L and the conditioning

316 coach in unison from a battery of suggestions in Richardson et al. (2017) on the day

317 of training. Table 1 outlines all completed exercises which include actual rate of

318 perceived exertion (RPE; Borg, 1982), exercise selection, duration, rest and

319 observational notes. Principles of training, in particular frequency and intensity were

320 adopted from Fu et al. (2011), however in contrast we did not incorporate a semi-

321 recumbent only approach at the start.

322 Table 1. Exercise Training Program including RPE and Observations

\begin{tabular}{lllll}
\hline Week 1 & $\begin{array}{l}\text { Duration } \\
\text { (sets/reps/time) }\end{array}$ & $\begin{array}{l}\text { Rest } \\
\text { Interval }\end{array}$ & RPE & Observations \\
\hline $\begin{array}{l}\text { Jog } \\
\text { Lower Trunk }\end{array}$ & $\begin{array}{l}\text { 3-mins } \\
\text { Rotation }\end{array}$ & $30 \mathrm{~s}$ & 15 & Speed 6.5 KMPH; comfortable. \\
Bridge & $2 \times 15 \mathrm{~s}$ & $30 \mathrm{~s}$ & 14 & $\begin{array}{l}\text { Limited glute activation. Hamstrings } \\
\text { dominant. }\end{array}$ \\
Abdominal Curl & 2 x 8 reps & $30 \mathrm{~s}$ & 15 & \\
\hline $\begin{array}{l}\text { Week 2 } \\
\text { Jog }\end{array}$ & 5 -mins & & 15 & $\begin{array}{l}\text { Speed 6.5 KMPH. Felt faint; 15-mins } \\
\text { recovery. }\end{array}$
\end{tabular}


IMPROVING QOL IN POTS

\begin{tabular}{|c|c|c|c|c|}
\hline $\begin{array}{l}\text { Lower Trunk } \\
\text { Rotation }\end{array}$ & $3 \times 12$ reps & $30 \mathrm{~s}$ & 10 & \\
\hline Bridge & $3 \times 15 s$ & $30 \mathrm{~s}$ & $14-15$ & Improved glute firing. \\
\hline Abdominal Curl & $3 \times 8$ reps & $30 \mathrm{~s}$ & 15 & \\
\hline \multicolumn{5}{|l|}{ Weeks 3-4 } \\
\hline Jog & 10-mins & & $15-16$ & $\begin{array}{l}\text { Speed } 6.5 \mathrm{KMPH} \text {. Felt steady was } \\
\text { able to talk throughout. }\end{array}$ \\
\hline Bridge & $3 \times 12$ reps & $30 \mathrm{~s}$ & 14 & \\
\hline Side Plank & $3 \times 15 s$ & $30 \mathrm{~s}$ & 15 & \\
\hline Hip Abduction & $3 \times 8$ reps & $30 \mathrm{~s}$ & $13-14$ & $\begin{array}{l}\text { Pain in left hip; stretched in } \\
\text { adduction to resolve. }\end{array}$ \\
\hline Plank on Elbows & $2 \times 20 s$ & $30 \mathrm{~s}$ & $15-16$ & \\
\hline Abdominal Curl & $3 \times 10$ reps & $30 \mathrm{~s}$ & 15 & Fatigued in last set. \\
\hline \multicolumn{5}{|l|}{ Weeks 5-6 } \\
\hline Jog (week 5) & 15-mins & & 15 & Speed 6.5 KMPH continuous. \\
\hline Jog (week 6) & 20-mins & & $15-16$ & $\begin{array}{l}\text { 5-mins at } 7.8 \mathrm{KMPH} \text {, followed by } \\
15 \text {-mins at } 6.5 \mathrm{KMPH} \text {. }\end{array}$ \\
\hline Stationary Bike & 5 -mins & & $16-17$ & $\begin{array}{l}\text { Interval; } 10 \text { s at } 100+\text { RPM followed } \\
\text { by } 20 \text { s at } 60 \text { RPM; repeat until time } \\
\text { elapsed. }\end{array}$ \\
\hline Sit to Stand & $3 \times 12$ reps & $30 \mathrm{~s}$ & $14-15$ & \\
\hline $\begin{array}{l}\text { Seated Shoulder } \\
\text { Press }\end{array}$ & $3 \times 12$ reps & $30 \mathrm{~s}$ & $14-15$ & Using 3KG dumbbells. \\
\hline $\begin{array}{l}\text { Dumbbell Bench } \\
\text { Press }\end{array}$ & $3 \times 12$ reps & $30 \mathrm{~s}$ & $13-14$ & Using 4KG dumbbells. \\
\hline Bridge & $3 \times 12$ reps & $30 \mathrm{~s}$ & $14-15$ & \\
\hline Side Plank & $3 \times 20$ secs & $30 \mathrm{~s}$ & 14 & \\
\hline Abdominal Curl & $3 \times 12$ reps & $30 \mathrm{~s}$ & 15 & \\
\hline \multicolumn{5}{|l|}{ Weeks 7-8 } \\
\hline Jog & 20-mins & & $15-16$ & $\begin{array}{l}\text { 5-mins at } 7.8 \mathrm{KMPH} \text {, followed by } \\
15 \text {-mins at } 6.5 \mathrm{KMPH} \text {. }\end{array}$ \\
\hline Stationary Bike & 5 -mins & & $16-17$ & $\begin{array}{l}\text { Interval - } 10 \text { s at } 100+\text { RPM followed } \\
\text { by } 20 \text { s at } 60 \text { RPM. Repeat until time } \\
\text { elapsed. }\end{array}$ \\
\hline Sit to Stand & $3 \times 8$ reps & $30 \mathrm{~s}$ & $15-16$ & $\begin{array}{l}\text { Holding } 5 \mathrm{KG} \text { kettlebell in both } \\
\text { hands. }\end{array}$ \\
\hline Hip Abduction & $3 \times 8$ reps & $30 \mathrm{~s}$ & $14-15$ & With resistance band. \\
\hline $\begin{array}{l}\text { Seated Shoulder } \\
\text { Press }\end{array}$ & $3 \times 8$ reps & $30 \mathrm{~s}$ & $15-16$ & Using $5 \mathrm{KG}$ dumbbells. \\
\hline Arm Curls & $3 \times 8$ reps & $30 \mathrm{~s}$ & $15-16$ & Using 4KG dumbbells. \\
\hline $\begin{array}{l}\text { Dumbbell Bench } \\
\text { Press }\end{array}$ & $3 \times 8$ reps & $30 \mathrm{~s}$ & 15 & Using 6KG dumbbells. \\
\hline Reverse Dip & $3 \times 30 s$ & $30 \mathrm{~s}$ & $15-16$ & \\
\hline
\end{tabular}


IMPROVING QOL IN POTS

$\begin{array}{llll}\text { Bridge } & 3 \times 12 \text { reps } & 30 \mathrm{~s} & 15 \\ \text { Abdominal Curl } & 3 \times 12 \text { reps } & 30 \mathrm{~s} & 15\end{array}$

323 Note . reps $=$ repetitions $; \mathrm{s}=$ seconds; mins $=$ minutes; $\mathrm{KMPH}=$ kilometres per hour;

$324 \mathrm{RPM}=$ revolutions per minute $\mathrm{KG}=$ kilograms.

325 In conjunction with supervised exercise sessions, a home-based program

326 consisting of two sessions per week, with at least 48 hours rest between sessions. The

327 aim of these exercises was to develop core, shoulder and lower extremity strength,

328 thus enhancing the body's skeletal pump efficiency. The home exercises were

329 reviewed each week to monitor adherence and to discuss progressions and

330 adaptations. We were pragmatic, and if this amount was not achievable, we decreased

331 the progressions or home exercise frequency.

332 As sessions progressed, goals were modified to: increase strength (in

333 particular legs and core), develop cardiovascular fitness, improve RoM in the hips,

334 resolve lower back pain, and enhance stability in the shoulder girdle. There were also

335 challenges that needed to be overcome related to time management, fatigue, and

336 monitoring POTS symptoms before, during and after exercise. To help during

337 exercise, the medical consultant prescribed vasoconstriction medication which was

338 taken before exercise.

\section{Evaluating the Intervention}

340 The WHOQOL-BREF was administered at baseline (week 0), week 8 at the

341 end of the combined intervention, and week 12. We also documented exercise

342 adherence. Table 2 shows the domain scores for the WHOQOL-BREF, plus the two

343 general life and health satisfaction questions similar to the format reported by Tito

344 and Hess (2017). Furthermore, we have included change as percentage from baseline 345 to week 12. 
IMPROVING QOL IN POTS

346 Table 2. WHOQOL-BREF scores by domain and time point.

Domain

\begin{tabular}{llll}
$\begin{array}{l}\text { Baseline } \\
\text { (week 0) }\end{array}$ & Week 8 & Week 12 & Change \% \\
\hline
\end{tabular}

\begin{tabular}{|c|c|c|c|c|}
\hline 1. Physical health* & 19 & 44 & 44 & 57.14 \\
\hline 2. Psychological* & 44 & 56 & 56 & 18.18 \\
\hline 3. Social relationships* & 25 & 44 & 44 & 37.50 \\
\hline 4. Environment* & 44 & 69 & 56 & 18.18 \\
\hline $\begin{array}{l}\text { Q1. How satisfied are } \\
\text { you with your life?** }\end{array}$ & 2 & 4 & 4 & 100.00 \\
\hline $\begin{array}{l}\text { Q2. How satisfied are } \\
\text { you with your health?** }\end{array}$ & 2 & 2 & 2 & 0.00 \\
\hline
\end{tabular}

349 The physical and environmental domains had the highest improvement from

350 baseline to week 8 with increases at $53.8 \%$ and $31.8 \%$ respectively. Exercise

351 adherence at week 8 was reported as a mean average of $83 \%$ based on three sessions

352 per week for eight-weeks which saw 20 out of 24 sessions completed.

353 Before exercise was completed at week 8, the psychologist interviewed R.L.

354 She discussed how the program had made her feel "less isolated...physically and

355 mentally healthier and stronger". She went on to say: "before the intervention when I

356 passed out it would leave me feeling unwell for a week or more, but now I feel more

357 in control. If it does happen, I just dust myself off and get on with it”. When asked to

358 give feedback for future developments of the POTS program, R.L. said that the social

359 interaction and having a team that cared about her "specific needs" was motivating

360 alone. Beyond the intervention R.L. planned to continue exercising with a personal

361 trainer, with the new aim to independently run. 


\section{IMPROVING QOL IN POTS}

environmental domain performing the worst at $-13.8 \%$, and the psychological domain

364 the best with an increase of 5\%. Overall, comparing total QOL baseline scores to

365 week 12, there was a $27.9 \%$ increase. All domain scores: physical (46.2\%),

366 psychological (25\%), social relationships (33.3\%), and environmental (13.6),

367 increased with specific questions showing no change for health (Q2), but a 100\% 368 increase for life satisfaction (Q1). The smaller variation between in the scores can 369 also be associated by the test-retest reliability (von Steinbüchel, Lischetzke, Gurny, \& 370 Eid, 2006). At week 12, an exit interview was conducted, and R.L. stated that the 371 intervention: "gave me the confidence to exercise", but from week 10 there was a 372 “decrease in using imagery because I felt back to my normal self”. Therefore, bi373 weekly booster sessions could be of benefit. contacted R.L. and were informed that she is continuing to exercise, although less regularly than when under supervision, and hopes to get back in the gym post

377 COVID-19. She informed us that she has decreased the use of medications including 378 antidepressants but continues to have good and bad days, stating: "the bad days are now very few, and a great deal more manageable". The current exercises conducted at 380 home were from the study (or small adaptations), and small self-administered lifestyle 381 modifications such as walking at least 10,000 steps daily were being completed 20382 weeks post intervention.

\section{Reflections and Recommendations}

We tried to approach challenges with reactive solutions driven partly by R.L.

385 We knew that the exercise program would have to be specific to the assessments, and 386 the progression of the sessions could be generally planned but were required to be 


\section{IMPROVING QOL IN POTS}

flexible due to the nature of POTS. The home exercise program was encouraged but again adapted to suit the reality of home training, including exercises that limited the potential for tachycardia and risk of falls. Additional challenges such as fatigue levels, loss of motivation, and time constraints, were overcome with positive dialogue, reinforcement of goals and a program that required just one weekly attendance for supervised sessions.

An initial issue occurred in week one. R.L wore a HR monitor during the session constantly checking her HR, which exacerbated exercise anxiety elevating her HR. Therefore, the psychologist and R.L. immediately left the laboratory and FIT was delivered through a brisk walk around the institution grounds. This became the initial method of delivery as it enabled the psychologist to review goals, help with imagery specific practice, and answer questions, whilst exercising and decreasing anxiety. However, this meant that no booster sessions were recorded in their entirety. A HR monitor was not worn again during exercise sessions, and although HR was often checked when using static equipment, most feedback was subjective through RPE. The main challenge with the FIT intervention was initially reminding R.L. to use the cue as her activating process that commences imagery. Imagery use, precisely motivation general mastery (see Paivio, 1985) was slow to start. R.L. could imagine achieving her exercise goal, but verbally reported limited positive self-imagery. The booster sessions were mutually beneficial at disseminating imagery application and three topics arose during conversations; examine goals and cues, explore opportunities to solve problems and overcome negative thoughts, and feedback on how to optimise vividness and controllability. We suggest that FIT imagery booster sessions use these three topics as the minimum requirement as it promotes learning and motivational goals. 


\section{IMPROVING QOL IN POTS}

Adjusting medication, work commitments and dietary patterns to fit into the

413 intervention was challenging for R.L. The medical consultant prescribed the best

414 medication to his knowledge to help with the incremental exercise program, and work

415 was compassionate allowing flexible working hours. Eating habits were self-adapted

416 to offset the increased energy expenditure resulting from exercise.

As an interdisciplinary team our main challenge was in meeting together, reviewing notes and developing a combined plan after week two. All nine members of

419 the interdisciplinary team involved in the project met after the initial interview and 420 assessments, then failed to meet together again. To maintain continuity weekly notes

421 were circulated and generally all parties responded inputting into the following weeks 422 program.

The aim of this study was to enhance the QOL through psychological and

424 physiological interventions. To do this we collaboratively set out specific goals,

425 which were modified based on achievement by R.L. and the research team. The initial 426 goal of jogging five-minutes was completed in week three after a series of small 427 setbacks and achievements, then goals evolved quickly which saw an observable 428 change in R.L. She was more talkative, upbeat and seemed confident, setting more 429 challenging goals such as jogging for 20-minutes. The overall increase in QOL due to 430 the intervention at week eight, we feel, was due to the combination of psychological 431 and physiological support, which assisted with the increase in confidence to exercise. 432 Whilst it would be beneficial to complete larger studies comparing the combined or 433 independent use of psychological and physiological interventions, there are clear 434 benefits to using a holistic individualised approach. A key benefit is the consistency 435 in scores from week 8 to 12 which demonstrate maintained QOL when support is 


\section{IMPROVING QOL IN POTS}

436

removed. We recommend that future researchers include periodic FIT booster support sessions after the intervention to support motivation through imagery use.

\section{Conclusion}

Within our specific professions we are experienced in collaborative structures and because of our person-centred approach, we assumed little about R.L.'s condition before completing assessments. POTS is complex and the training program included is only a rough guide for practitioners. Generic exercise suggestions for POTS (Fu et al., 2011; Richardson et al., 2017) such as interval training would not have worked for R.L. in the first few weeks, so we suggest a collaborative approach that engages the specialists and client in mutual conversations that are focused on tangible goals. We were very fortunate to have the expertise available and acted promptly to get the project underway. Applying neutrality, an essential skill for FIT, to this project was perhaps the most challenging part. We tried not to show emotion from R.L.'s highs and lows during setbacks and achievements, but we developed a connection as we learned from her. Motivational interventions such as MI and FIT focus on unambiguous goals, which as practitioners we fully engage in. These goals are clientcentred, and team driven through mutual processes, resulting in behaviour change from us all. We recommend that practitioners who work with individuals that have low self-efficacy become trained in motivational goal setting. This creates a learning environment that cultivates empathy and autonomy, key factors for improving QOL. Overall, we supported R.L. by rekindling the enjoyment she once had whilst participating in health and exercise activities and were able to collaboratively support behavioural change by increasing intrinsic motivation. 
IMPROVING QOL IN POTS

\section{References}

Agarwal, S. K. (2012). Cardiovascular benefits of exercise. International Journal of General Medicine, 5, 541. doi:10.2147/IJGM.S30113

Anderson, J. W., Lambert, E. A., Sari, C. I., Dawood, T., Esler, M. D., Vaddadi, G., \& Lambert, G. W. (2014). Cognitive function, health-related quality of life, and symptoms of depression and anxiety sensitivity are impaired in patients with the postural orthostatic tachycardia syndrome (POTS). Frontiers in Physiology, 5, 230. doi:10.3389/fphys.2014.00230

Andrade, J., Khalil, M., Dickson, J., May, J., \& Kavanagh, D. J. (2016). Functional Imagery Training to reduce snacking: Testing a novel motivational intervention based on Elaborated Intrusion theory. Appetite, 100, 256-262. doi:10.1016/j.appet.2016.02.015

Bhaskar, R. (2013). A realist theory of science. Routledge, London, UK.

Borg, G. A. (1982). Psychophysical bases of perceived exertion. Medicine \& Science in Sports \& Exercise, 14(5), 377-381. doi:10.1249/00005768-19820500000012

Campbell, A., \& Hausenblas, H. A. (2009). Effects of exercise interventions on body image: A meta-analysis. Journal of Health Psychology, 14(6), 780-793. doi:10.1177/1359105309338977

Conner, R., Sheikh, M., \& Grubb, B. (2012). Postural orthostatic tachycardia syndrome (POTS): Evaluation and management. British Journal of Medical Practice, 5(4), 540.

De Moor, M. H. M., Beem, A. L., Stubbe, J. H., Boomsma, D. I., \& De Geus, E. J. C. (2006). Regular exercise, anxiety, depression and personality: a populationbased study. Preventive medicine, 42(4), 273-279. doi:10.1016/j.ypmed.2005.12.002

Duckworth, A. L., Kirby, T. A., Gollwitzer, A., \& Oettingen, G. (2013). From fantasy to action: Mental contrasting with implementation intentions (MCII) improves academic performance in children. Social Psychological and Personality Science, 4(6), 745-753. doi:10.1177/1948550613476307

Flack, T., \& Fulton, J. (2018). Quality of life in postural orthostatic tachycardia syndrome (PoTS): before and after treatment. British Journal of Cardiology, $25,140-142$. 


\section{IMPROVING QOL IN POTS}

492

493

494

495

496

497

498

499

500

501

502

503

504

505

506

507

508

509

510

511

512

513

514

515

516

517

518

519

520

521

522

523

524

Fu, Q., \& Levine, B. D. (2018). Exercise and non-pharmacological treatment of POTS. Autonomic Neuroscience, 215, 20-27. doi:10.1016/j.autneu.2018.07.001

Fu, Q., VanGundy, T. B., Shibata, S., Auchus, R. J., Williams, G. H., \& Levine, B. D. (2011). Exercise training versus propranolol in the treatment of the postural orthostatic tachycardia syndrome. Hypertension, 58(2), 167-175. doi:10.1007/s10286-010-0091-5

Galbreath, M. M., Shibata, S., VanGundy, T. B., Okazaki, K., Fu, Q., \& Levine, B. D. (2011). Effects of exercise training on arterial-cardiac baroreflex function in POTS. Clinical Autonomic Research, 21(2), 73-80. doi:10.1007/s10286-0100091-5

Gholami, A., Jahromi, L. M., Zarei, E., \& Dehghan, A. (2013). Application of WHOQOL-BREF in measuring quality of life in health-care staff. International journal of preventive medicine, 4(7), 809.

Kavi, L., Gammage, M. D., Grubb, B. P., \& Karabin, B. L. (2012). Postural tachycardia syndrome: multiple symptoms, but easily missed. British Journal of General Practice, 62(599), 286-287. doi:10.3399/bjgp12X648963

Kizilbash, S. J., Ahrens, S. P., Bruce, B. K., Chelimsky, G., Driscoll, S. W., HarbeckWeber, C., ... \& Pianosi, P. T. (2014). Adolescent fatigue, POTS, and recovery: a guide for clinicians. Current Problems in Paediatric and Adolescent Health Care, 44(5), 108-133. doi:10.1016/j.cppeds.2013.12.014

Lang, P. J. (1979). A bio-informational theory of emotional imagery. Psychophysiology, 16(6), 495-512. doi:10.1111/j.1469-8986.1979.tb01511.x

Miller, W. R., \& Rollnick, S. (2012). Motivational interviewing: Helping people change. Guilford press.

Moon, J., Kim, D. Y., Byun, J. I., Sunwoo, J. S., Lim, J. A., Kim, T. J., ... \& Park, K. I. (2016). Orthostatic intolerance symptoms are associated with depression and diminished quality of life in patients with postural tachycardia syndrome. Health and Quality of Life Outcomes, 14(1), 144. doi:10.1186/s12955-0160548-x

Paivio, A. (1985). Cognitive and motivational functions of imagery in human performance. Canadian journal of applied sport sciences. Journal Canadien des Sciences Appliquées au Sport, 10(4), 22S-28S. 


\section{IMPROVING QOL IN POTS}

Pal, S., Radavelli-Bagatini, S., \& Ho, S. (2013). Potential benefits of exercise on blood pressure and vascular function. Journal of the American Society of Hypertension, 7(6), 494-506. doi:10.1016/j.jash.2013.07.004

Raj, S. R. (2013). Postural tachycardia syndrome (POTS). Circulation, 127(23), 23362342. doi:10.1161/CIRCULATIONAHA.112.144501

Richardson, M. V., Nordon-Craft, A., \& Carrothers, L. (2017). Using an exercise program to improve activity tolerance in a female with postural orthostatic tachycardia syndrome: a case report. Physiotherapy Theory and Practice, 33(8), 670-679. doi:10.1080/09593985.2017.1328719

Rhodes, J., May, J., Andrade, J., \& Kavanagh, D. (2018). Enhancing grit through functional imagery training in professional soccer. The Sport Psychologist, 32(3), 220-225. doi:10.1123/tsp.2017-0093

Rorty, R. (1991). The priority of democracy to philosophy. Objectivity, relativism, and truth: Philosophical papers, 1, 175-196.

Schondorf, R., Benoit, J., Wein, T., \& Phaneuf, D. (1999). Orthostatic intolerance in the chronic fatigue syndrome. Journal of the Autonomic Nervous System, 75(2-3), 192-201. doi:10.1016/S0165-1838(98)00177-5

Sharma, A., Madaan, V., \& Petty, F. D. (2006). Exercise for mental health. Primary Care Companion to the Journal of Clinical Psychiatry, 8(2), 106-106. doi:10.4088/pcc.v08n0208a

Shibata, S., Fu, Q., Bivens, T. B., Hastings, J. L., Wang, W., \& Levine, B. D. (2012). Short-term exercise training improves the cardiovascular response to exercise in the postural orthostatic tachycardia syndrome. The Journal of Physiology, 590(15), 3495-3505. doi:10.1113/jphysiol.2012.233858

Smith, D. E., Heckemeyer, C. M., Kratt, P. P., \& Mason, D. A. (1997). Motivational interviewing to improve adherence to a behavioral weight-control program for older obese women with NIDDM: a pilot study. Diabetes Care, 20(1), 52-54. doi:10.2337/diacare.20.1.52

Solbrig, L., Whalley, B., Kavanagh, D. J., May, J., Parkin, T., Jones, R., \& Andrade, J. (2019). Functional imagery training versus motivational interviewing for weight loss: a randomised controlled trial of brief individual interventions for overweight and obesity. International Journal of Obesity, 43(4), 883-894. doi:10.1038/s41366-018-0122-1 


\section{IMPROVING QOL IN POTS}

558 Tito, C., \& Hess, J. B. (2017). Aquatic Therapy for a Patient with Postural Orthostatic

559

560
Tachycardia Syndrome: a Case Report. Internet Journal of Allied Health Sciences and Practice, 15(3), 10.

von Steinbüchel, N., Lischetzke, T., Gurny, M., \& Eid, M. (2006). Assessing quality of life in older people: psychometric properties of the WHOQOL-BREF. European Journal of Ageing, 3(2), 116-122. doi:10.1007/s10433-006-0024-2

Whoqol Group. (1995). The World Health Organization quality of life assessment (WHOQOL): position paper from the World Health Organization. Social science \& medicine, 41(10), 1403-1409. doi:10.1016/0277-9536(95)00112-K

Williams, S. E., Cooley, S. J., \& Cumming, J. (2013). Layered stimulus response training improves motor imagery ability and movement execution. Journal of Sport and Exercise Psychology, 35(1), 60-71. doi:10.1123/jsep.35.1.60

Winker, R., Barth, A., Bidmon, D., Ponocny, I., Weber, M., Mayr, O., ... \& Haber, P. (2005). Endurance exercise training in orthostatic intolerance: a randomized, controlled trial. Hypertension, 45(3), 391-398. doi:10.1161/01.HYP.0000156540.25707.af

World Health Organization. (1997). Measuring quality of life: The World Health Organization quality of life instruments (the WHOQOL-100 and the WHOQOL-BREF). WHOQOL-measuring quality of life. 